Bull. Chem. Soc. Ethiop. 2020, 34(1), 1-11.

ISSN 1011-3924

(C) 2020 Chemical Society of Ethiopia and The Authors

Printed in Ethiopia

DOI: https://dx.doi.org/10.4314/bcse.v34i1.1

\title{
CLARIFICATION OF THE ALGERIAN GRAPE JUICE AND THEIR EFFECTS ON THE JUICE QUALITY
}

\author{
Soraya Mazrou ${ }^{1}$, Mohammed Messaoudi ${ }^{2 *}$, Samir Begaa ${ }^{2}$, Christophe Innocent ${ }^{3}$ and \\ Djamaleddine Akretche ${ }^{1}$ \\ ${ }^{1}$ Laboratory of Hydrometallurgy and Inorganic Molecular Chemistry, USTHB Faculty of \\ Chemistry PO BOX 32 El Alia Bab Ezzouar, 16111 Algiers, Algeria \\ ${ }^{2}$ Nuclear Research Centre of Birine, P.O. Box 180, Ain Oussera, 17200 Djelfa, Algeria \\ ${ }^{3}$ Institut Européen des Membranes, CNRS UMR 5635 Cc 047, Place Eugène Bataillon 34095, \\ Montpellier Cedex 5, France
}

(Received July 22, 2019; Revised February 7, 2020; Accepted February 6, 2020)

\begin{abstract}
The aim of this study was to find a good clarification method to eliminate the substances in Algerian grape juice and study the effects of the clarification agents on juice quality. The clarified grape juice was subjected to different treatments, namely bentonite, gelatin, combination of gelatin and bentonite, then stored for 4 weeks. The effects of fining treatment by determining the critical micillary concentration of each agent used accelerated stability test on turbidity, tannin contents (ethanol index, condensed tannins, total polyphenol and anthocyanins) and microbiological quality of clarified grape juice were evaluated during storage. Fining treatment and storage had a significant $(p<0.05)$ effect on turbidity, tannins, total polyphenol, condensed tannins and anthocyanins. However, a better percentage elimination was noted for freshly squeezed grape juice with a combination of gelatin and bentonite corresponding to a turbidity of $6.5 \mathrm{NTU}$. The clarifiers separately gave lower removal rates than average, up to $83 \%$ of tannins present in the freshly squeezed juice has been eliminated using the bentonite. The results obtained are very satisfactory since we were able to obtain a clear juice of good microbial quality while ensuring the preservation of the organoleptic and nutritional qualities during the treatment and the storage of the juice.
\end{abstract}

KEY WORDS: Algerian grape juice, Bentonite, Gelatin, Turbidity, Cation exchange, Clarification

\section{INTRODUCTION}

Fruit juice accommodates varying tastes and can serve as a fruit substitute during a snack or meal. Drinking pure fruit juice will supply some of the vitamins and minerals you would get from eating a whole piece of fruit. Fruit juice is appreciated and recommended for all ages. However, the modern industry is still seeking clarification methods to eliminate the substances that cause disorders or sediment [1-4]. Stabilization of beverage by means of gelatin and bentonite is a prevalent treatment in the juice industry. For obtaining a clear juice, substances responsible for the disorders or sediment should be removed. This process is known as clarification, or fining, one of the most important unit operations in fruit juice processing [512]. Differences in the nature of ionic charges of protein, polyphenols and the fining agents induce flocculation and sedimentation and result in the removal of these potentials for haze precursors from solution. Fining is one of the least expensive operations in juice production but one that can have the greatest impact on juice quality. Fining trials should always be done at several levels to ensure that the fining objective is achieved using the smallest possible amount of fining agent $[5,13]$. Fining helps to remove active haze precursors and thus, decreases the potential for haze formation during storage, while providing more limpid juice sediment $[6,7,9$, $14,15]$. This process helps to overcome the enzymatic treatment, which is very expensive [6].

*Corresponding author. E-mail: messaoudi2006@yahoo.fr

This work is licensed under the Creative Commons Attribution 4.0 International License 
Over the past decade, researchers and food manufacturers have become increasingly interested in polyphenols. The chief reason for this interest is the recognition of the antioxidant properties of polyphenols, their high abundance in our diet, and their probable role in the prevention of various diseases associated with oxidative stress, such as cancer and cardiovascular diseases. Polyphenols in fruit juices polymerise, through oxidative reactions into larger molecules, which precipitate out of solution and become visible as haze. Alternatively, they can also form complexes with other macromolecules such as proteins, starch and divalent metal ions [16-19].

The qualities particularly interesting of bentonite have attracted the attention of chemists. Indeed, its properties such as its high exchange capacity, and its large adsorption capacity, and resistance to chemical attack are as bentonite has now become essential in many industrial applications including the food industry as purification and clarification agent of solutions $[20$, 21]. The raw local clay is found in abundance in the Hammam-Boughrara deposits in Maghnia (Tlemcen).

Accordingly, the present work was carried out to clarify the black grapes juice (cinsault) through removal of tannins using gelatin and the local clay, an acidified bentonite to obtain a clear juice. The results obtained in this study could be used as a database in the Food Industry production and agriculture research.

\section{EXPERIMENTAL}

\section{Sampling}

The sample of black raisin grapes to be analyzed was collected in the area belonging to the Algerian Cinsault variety and botanically known as Vitis vinifera $\mathrm{L}$. The land area is $650 \mathrm{~m}^{2}$ and the samples were taken at four homes, each one of about $1 \mathrm{~kg}$. The raisin was pressed and the juice obtained at the values of $\mathrm{pH}$ and turbidity of $(4.6 \pm 0.1)$ and $(152 \mathrm{NTU})$, respectively, was subjected to several clarification tests using different fining agents.

The acid-activated bentonite was obtained from the Company National Non-ferrous in Algeria. The clay is conditioned in $50 \mathrm{~kg}$ bags of 1 ton $250 \mathrm{~kg}$ covered and hooped pallets.

\section{Fining treatment}

We have previously determined the doses of the clarifying agents used in this study, namely bentonite clay and animal gelatin [21]. Their concentration ranges are 50-100 $\mu \mathrm{g} / \mathrm{L}$. The clarifiers are not directly added, each of them is first prepared in solution as a suspension in water depending on temperature, the proportion and time of solubilisation. The bentonite was prepared in $10 \%$ solution in distilled water at room temperature under constant and moderate agitation using a magnetic stirrer and we let the suspension swell for 6 to 12 hours before use.

Hydrolized gelatin was prepared in $5 \%$ solution in distilled water at $60{ }^{\circ} \mathrm{C}$ under constant and moderate agitation. In $100 \mathrm{~mL}$ of freshly squeezed grape juice, we introduced, using a micropipette, the required dosage of clarifying agent. This step was accompanied by agitation. We let the solutions stand for one hour to monitor the flocculation. The complex formed was removed by filtration. For each test, we measured the turbidity of the filtrate. Sodium benzoate was added as a preservative. The clarified juice was bottled into dark glass bottles and then subjected to final pasteurization at $90{ }^{\circ} \mathrm{C}$ for $5 \mathrm{~min}$ in an industrial production chain for fruit juice.

\section{Turbidity measurement}

Samples were placed in a cell holder for turbidity measurements. Haze sediment in the juice was re-suspended prior to measuring sample turbidity by gently rocking immediately before 
measurements were taken [22]. The turbidity of the juice was determined using a turbidity meter (Merck Turbidiquant 1500T) and was reported as Nephelometric Turbidity Units (NTU).

\section{Conventional methods}

Colorimetric methods give an estimate of phenol content and are rapid and economical to perform compared to other methods requiring expensive equipment.

\section{Tannin determination: index of ethanol}

Using the property of ethanol to precipitate proteins, polysaccharides and tannins related to them. An aliquot of juice $(1 \mathrm{~mL})$ was mixed with a few milliliters of deionised water, $9 \mathrm{~mL}$ of $95 \%$ ethanol and completing with water distilled in a $100 \mathrm{~mL}$ flask. Samples of juice $(5 \mathrm{~mL})$ were completed with $95 \%$ ethanol, leaving at room temperature for $48 \mathrm{~h}$, centrifuging and diluting the tenth. The absorbance of each solution was measured at $280 \mathrm{~nm}$ with UV-VIS-NIR spectrophotometer (Model V-570).

\section{Total polyphenols determination}

Total polyphenol content was determined using the Folin-Ciocalteu assay [17]. This method is based on oxidation-reduction reactions, using gallic acid as the standard. The yellow FolinCiocalteu reagent (consisting of a phosphotungstic acid complex $\mathrm{H}_{3} \mathrm{PW}_{12} \mathrm{O}_{40}$ and phosphomolybdic acid $\mathrm{H}_{3} \mathrm{PMo}_{12} \mathrm{O}_{40}$ ) is reduced by the phenols to a mixture of blue-violet oxides. Values were given in gallic acid equivalents. Samples of juice $(0.5 \mathrm{~mL})$ were mixed with $2.5 \mathrm{~mL}$ of Folin-Ciocalteu reagent (diluted 1:10). Two milliliters of saturated sodium carbonate $(75 \mathrm{~g} / \mathrm{L})$ was added to the mixture and shaken. Heat the solution for $5 \mathrm{~min}$ at $50{ }^{\circ} \mathrm{C}$ and noting the change in color from yellow to blue. The absorbance of the solution was measured at 760 $\mathrm{nm}$.

\section{Condensed tannins determination}

It is based on the reduction of phosphomolybdic acid and tungstic in alkaline medium, in the presence of tannins to give a blue color whose intensity is measured at $760 \mathrm{~nm}$ under $1 \mathrm{~cm}$ thick. Even as a protocol relating to the determination of total polyphenols already described in previous paragraph, values were given in tannic acid equivalents.

\section{Anthocyanins determination}

The determination of anthocyanins [18]. In grape juice is made using two properties due to their structure: (i) change their color depending on the $\mathrm{pH}$ and (ii) transformation into colorless derivatives under the action of bisulfite ions. Thus, the variation of the absorbance read at 520 $\mathrm{nm}$ after addition of excess bisulfite ions is proportional to the anthocyanin content. Samples of juice $(1 \mathrm{~mL})$ were mixed with $1 \mathrm{~mL}$ of ethanol $(95 \%)$ acidified in $0.1 \%$ pure hydrochloric acid and $20 \mathrm{~mL}$ of hydrochloric acid (35\%) diluted to $2 \%$ in distilled water.

Tank"A" was prepared with $5 \mathrm{~mL}$ of mixture and was added with $2 \mathrm{~mL}$ of demineralised water.

Tank"B" was prepared with $5 \mathrm{~mL}$ of mixture and was added to $2 \mathrm{~mL}$ of solution of sodium bisulfite $(150 \mathrm{~g} / \mathrm{L})$. The tanks were treated without bisulfite to avoid any discoloration by the residues.

\section{Microbiological analysis}

Total mold and yeast count of clarified grape juice were conducted according to a dilution technique sowing. We realized from $100 \mathrm{~mL}$ of grape juice, three successive dilutions with 
physiological saline: $10^{-1}, 10^{-2}$ and $10^{-3}$. Each dilution $(0.1 \mathrm{~mL})$ was inoculated across the surface of the agar plate using potato dextrose agar culture medium. The incubation of the Petri dishes was done in an oven at $25^{\circ} \mathrm{C}$ for 7 days. The enumeration of total yeasts and molds was achieved through an electronic counter and expressed as Colony Forming Units per milliliter $(\mathrm{CFU} / \mathrm{mL})$.

\section{Physical parameters determination}

Some physical parameters were determined as Brix and index refractive using benchtop refractometer and viscosity using digital display viscosimeter (Model SNB-1).

\section{Infra-red (IR) spectroscopy analysis}

The absorption phenomenon in the IR domain is related to the transitions in the energy molecular vibrations. The study of the IR spectra indicates the presence or absence of characteristic bands of groups such as -OH, Si-O, Si-O-M and M-O-H. The IR absorption spectra were recorded between 4000 and $400 \mathrm{~cm}^{-1}$ using an IR spectrophotometer «Spectrum One FT-IR». The method of preparation consists in obtaining pellets containing 5 to $7 \%$ of the sample by compression with potassium bromide.

\section{Accelerated stability test}

The clarified grape juice was subjected to the accelerated stability test, pasteurized and stored for 4 weeks at room temperature in dark glass bottles [16, 23].

\section{Exchange cation}

The exchange method used in our work is the batch method [10]. The suspension clay is subjected to agitation of $40 \mathrm{rpm}$ using a shaker AGITELEC brand. The cations $\mathrm{Ca}^{2+}$ and $\mathrm{K}^{+}$were determined by flame photometer brand JENWAY PFP7 and the cations $\mathrm{Na}^{+}$and $\mathrm{Mg}^{2+}$ with plasma torch brand VISTA-PORO.

\section{Determination of equilibrium constant}

The equilibrium constant is given by the following formula:

$$
K_{A / B}=\frac{[B]_{C l} \times[A]_{S}}{[B]_{S} \times[A]_{C l}}
$$

$[\mathrm{A}]_{\mathrm{Cl}}$ and $[\mathrm{B}]_{\mathrm{Cl}}$ are concentration of $\mathrm{A}$ and $\mathrm{B}$ in the clay. $[\mathrm{A}]_{\mathrm{S}}$ and $[\mathrm{B}]_{\mathrm{s}}$ are concentration of $\mathrm{A}$ and $\mathrm{B}$ in the solution.

\section{Determination of partition coefficient}

The partition coefficient is given by the following formula:

$P_{M}=\frac{C_{C l}}{C_{s}}$

$\mathrm{C}_{\mathrm{Cl}}$ is concentration of the element $\mathrm{M}$ in the clay in moles per liter per gram of clay and $\mathrm{C}_{\mathrm{S}}$ is concentration of the element $\mathrm{M}$ in moles per liter in the solution. Both concentrations were measured at equilibrium based of the initial concentration of the element $\mathrm{M}$ in the solution [10, 20]. 


\section{Statistical Analysis}

The statistical analysis [24], used for the error calculation of the different values obtained during the experiments is the inverse student test, where the values are within a next confidence interval between a lower limit and upper limit:

$\left[\bar{X}-\left(t_{N-1,1-\alpha / 2} * S_{x}^{\prime}\right)\right] \leq \alpha \leq\left[\bar{X}+\left(t_{N-1,1-\alpha / 2} * S_{x}^{\prime}\right)\right]$

$\bar{X}$ « average value compared to $\mathrm{N}$ tests, $\bar{X}=\frac{\sum_{i}^{N} x i}{N}$

$S_{x}^{\prime}$ : average standard deviation, $S=\sqrt{\frac{\sum_{i}^{N}\left(x i-x^{\prime}\right)\left(x i-x^{\prime}\right)}{N-1}}$ and $S_{x}^{\prime}=S / \sqrt{N}$

$\boldsymbol{t}_{N-1,1-\alpha / 2}$ : inverse student test for a probability $(1-\alpha / 2)$ of 0.05 . All statistical tests were done by excel using the inverse student test.

\section{RESULTS AND DISCUSSION}

\section{Turbidity}

A significant $(p<0.05)$ decrease in turbidity was observed for the juice treated respectively with bentonite, gelatin and a combination of gelatin and bentonite (Figure 1) since the initial turbidity of a freshly squeezed and unclarified juice equal to around 150 NTU. Results indicated that the use of gelatin and bentonite separately, juices were partially clarified (NTU $\approx 40$ and $\mathrm{NTU} \approx 30$, respectively). Moreover, with the combination of gelatin and bentonite (synergism effect), juices were practically clarified and turbidity was drastically reduced (NTU $\approx 5$ ).

We can conclude that a better elimination is observed for a combination of gelatin and bentonite $(600 \mu \mathrm{L}$ in gelatin and $950 \mu \mathrm{L}$ in bentonite) where we have reached a percentage of elimination equal to $95.7 \%$. To confirm this result, we carried out the measurements of refractive index and viscosity. The results show a decrease in the refractive index from 1.4 to 1.3 and viscosity from 11.1 to 8.6. This confirms the removal of suspended solids.

\section{Tannins}

We can conclude that there is an elimination of various tannins and anthocyanins present in grapes juice after clarification with the Algerian acidified clay at the concentration of $900 \mu \mathrm{L}$ (Table 1).

Table 1. Measurement of different tannins contents and anthocyanins $(n=4)$.

\begin{tabular}{|l|c|c|c|c|}
\hline Parameter & Index of ethanol & Total polyphenol & Condensed tannins & Anthocyanins \\
\hline Initial concentration & $76.6 \%$ & $490 \mathrm{mg} / \mathrm{L}$ & $1510 \mathrm{mg} / \mathrm{L}$ & $43.4 \mathrm{mg} / \mathrm{L}$ \\
\hline Final concentration & $54.2 \%$ & $195 \mathrm{mg} / \mathrm{L}$ & $573 \mathrm{mg} / \mathrm{L}$ & $14.1 \mathrm{mg} / \mathrm{L}$ \\
\hline Elimination percentage (\%) & 29.2 & 60.2 & 62.1 & 67.5 \\
\hline
\end{tabular}

\section{Microbial stability test}

The microbiological results of clarified juice after microbial accelerated stability test of five days show that it is free of total yeasts and total molds. We can conclude that the clarified juice after storage for 4 weeks possessed a good microbiological quality. 


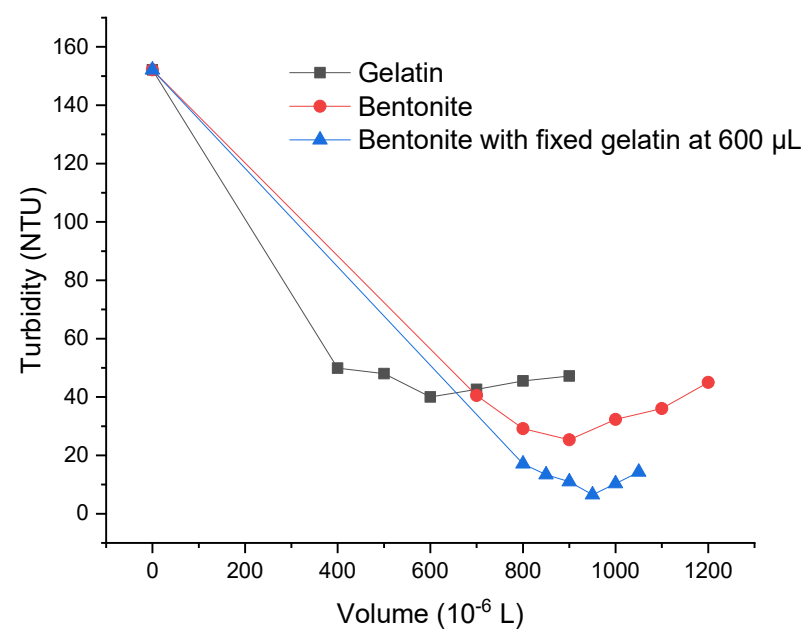

Figure 1. Variation of turbidity on the volume of different clarifiers.

\section{Measurement of some juice parameters}

The measurement results of some parameters juice show that only the turbidity increases, and presents as follows for clarified juice and clarified juice after accelerated stability test, respectively, where the results showed that increased in turbidity (NTU) from $(6.5 \pm 0.1)$ to $(10.1 \pm 0.0)$ and decreased in viscosity (Pa.s) from 8.6 to 8.4. There was no change in the results of the Density $\left(1.1^{\circ}\right)$ and soluble solids (15 Brix). Indeed, a slight deposit was found during storage. We propose then to analyze the precipitate by using the FT-IR spectroscopy and comparing with the precipitate of non-clarified juice (Figure 2(a)). All samples were characterized by FTIR using Perkin Elmer spectrophotometer (Spectrum One model). All spectra were recorded at a resolution of $2 \mathrm{~cm}^{-1}$ and total of 32 scans were accumulated for each spectrum along with the background. We note that both spectra have the same speed for the wavelength range from $400 \mathrm{~cm}^{-1}$ to $4000 \mathrm{~cm}^{-1}$ with more intense peaks and some slightly displaced peaks in the spectrum of the treated juice. A wide and strong band is observed at around 3400 and $3200 \mathrm{~cm}^{-1}$ corresponding to the associated $\mathrm{O}-\mathrm{H}$ vibrator elongation. This is explained by the presence of polymeric structures where the intramolecular hydrogen bonds are important. The spectral region from $600 \mathrm{~cm}^{-1}$ to $1500 \mathrm{~cm}^{-1}$, has been expanded for clarity (Figure 2(b)). Figure 2(b), shows that both treated and untreated samples have the same absorbance, but always more intense peaks in the spectrum of treated juice. However, some peaks have shifted slightly. We can conclude that the two spectra are identical and correspond to the tannins or different polyphenols present in the juice and peak intensities are due to the high concentration of treated juice. The filing occurred during storage results from $4.3 \%$ of the trouble (not eliminated).

\section{Cation exchange}

We prepared different concentrations of $10 \%$ of clay suspension. Figure 3(a), gives the variation in the quantity of exchanged $\mathrm{K}^{+}$over a period of time for different amounts of clay. We note from this figure that the exchange happens in the first $10 \mathrm{~min}$ and then a level of saturation is reached. The exchange is almost identical for different amounts of clay and then we drew the initial slope of the curves $C(t)$ depending on the amount of clay to view the best exchange 
(Figure 3(b)). The initial slope of the curve $d C / d t$ obtained is in the form of a bell having a maximum exchange of $0.08 \%$ clay.
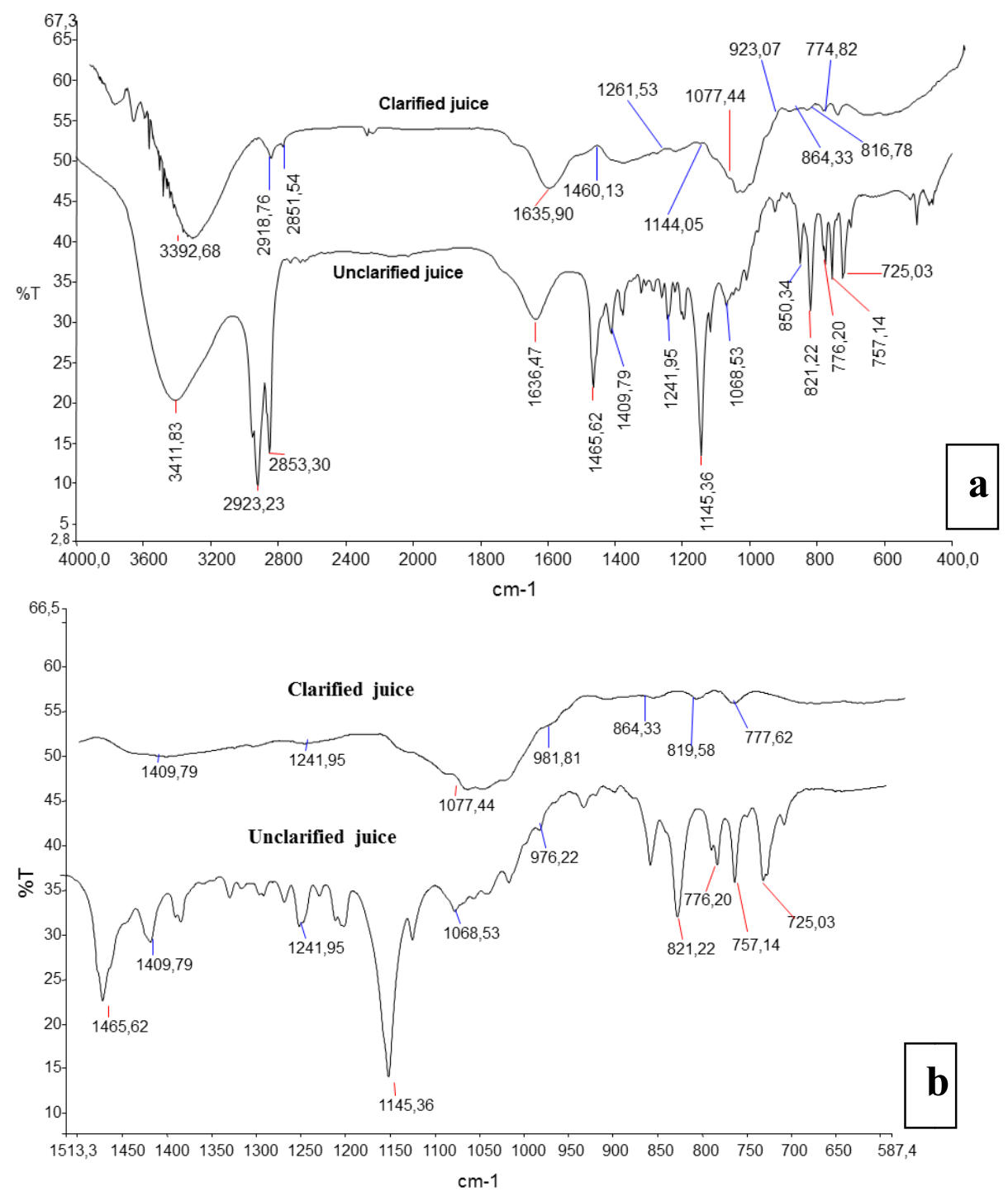

Figure 2. IR spectra of precipitates of clarified and unclarified juices (a), and IR spectrum of clarified and unclarified juices in $1500-600 \mathrm{~cm}^{-1}$ region (b).

After fixing the amount of clay, we studied the effect of initial concentration on the exchange. $0.08 \%$ of suspension is inflated for at least 6 hours. The exchange is made for different fixed concentrations of the initial solution of $\mathrm{K}^{+}(0.01,0.025,0.05$ and $0.1 \mathrm{M})$ according the time. We note that the exchange quantity is almost the same for all concentrations 
studied. And from Figure 3(c), the exchange rate increases with the initial concentration of the solution from $85.1 \pm 0.016 \%$ to $(96.1 \pm 0.1 \%)$. Then the optimum conditions of exchange are at $0.08 \%$ of the suspension clay in $100 \mathrm{~mL}$ of distilled water and $0.01 \mathrm{M}$ of the cation in the initial solution.

Event of a single ion

From Figure 3(d), we note that the exchange occurs in the four solutions in 5 min and then a state of saturation is reached. It appears that the ion binding on montmorillonite follows an affinity for cations and it is observed the following order $\mathrm{Ca}^{2+}>\mathrm{Mg}^{2+}>\mathrm{K}^{+}>\mathrm{Na}^{+}$. And the exchange constant calculated from formula (I) confirms the affinity previously found (Table 1), since we find the following order; $\left(K_{\mathrm{Ca}}{ }^{2+}=29.6 \pm 8.7 \times 10^{-05}\right)>\left(K_{\mathrm{Mg}}{ }^{2+}=23 \pm 1 \times 10^{-04}\right)>\left(K_{K}{ }^{+}=\right.$ $\left.15.1 \pm 4 \times 10^{-04}\right)>\left(K_{\mathrm{Na}}^{+}=4.9 \pm 6 \times 10^{-05}\right)$.
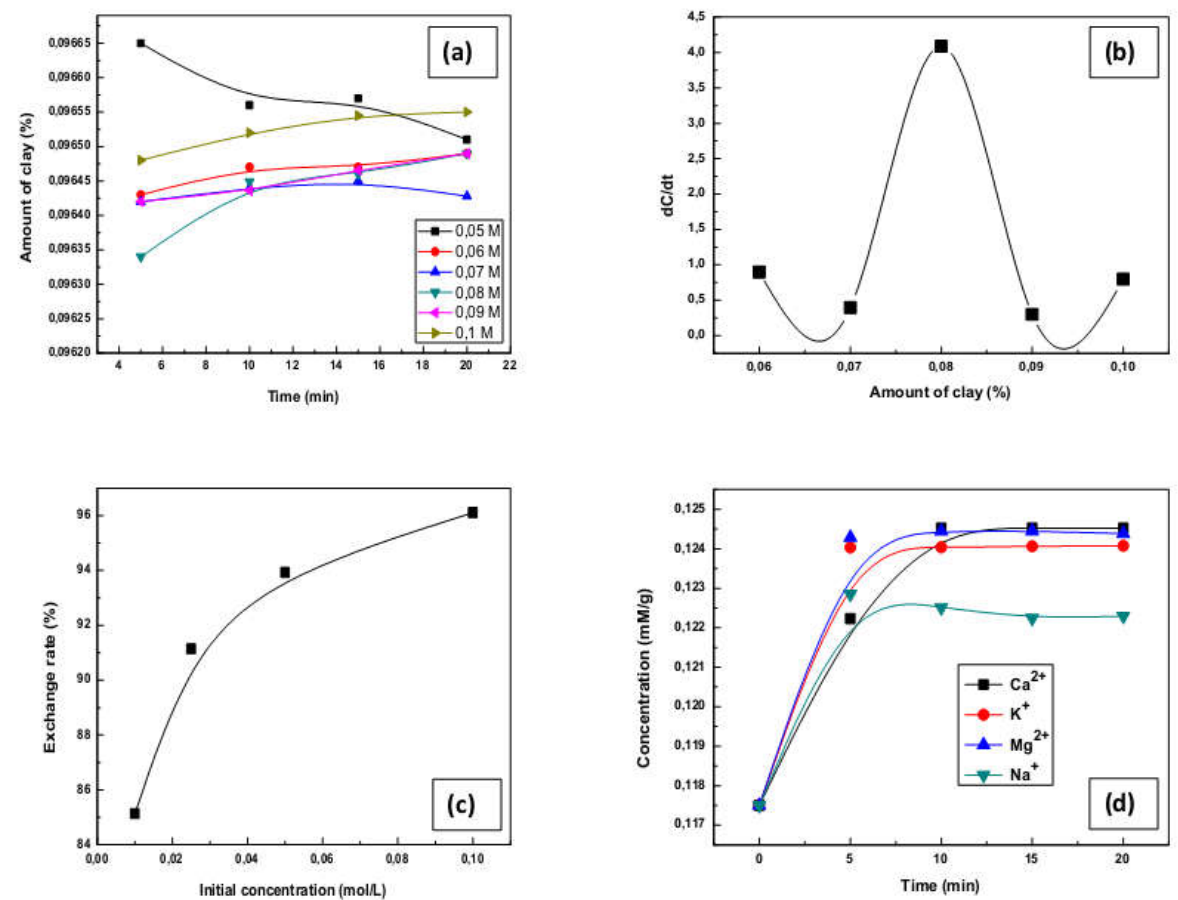

Figure 3. Exchange quantity according time at different concentrations of the suspension (a), exchange rate based on the amount of clay (b), variation of exchange quantity according the concentration of initial solution (c), and exchange quantity according the time for each cation (d).

\section{Event of a quaternary}

The partition coefficients calculated from formula (II) for the quaternary $\mathrm{Mg}^{2+}$ and $\mathrm{Na}^{+}$are very low compared to those obtained for $\mathrm{K}^{+}$and $\mathrm{Ca}^{2+}$ which have the same values up to 5 min (Figure $4)$. 


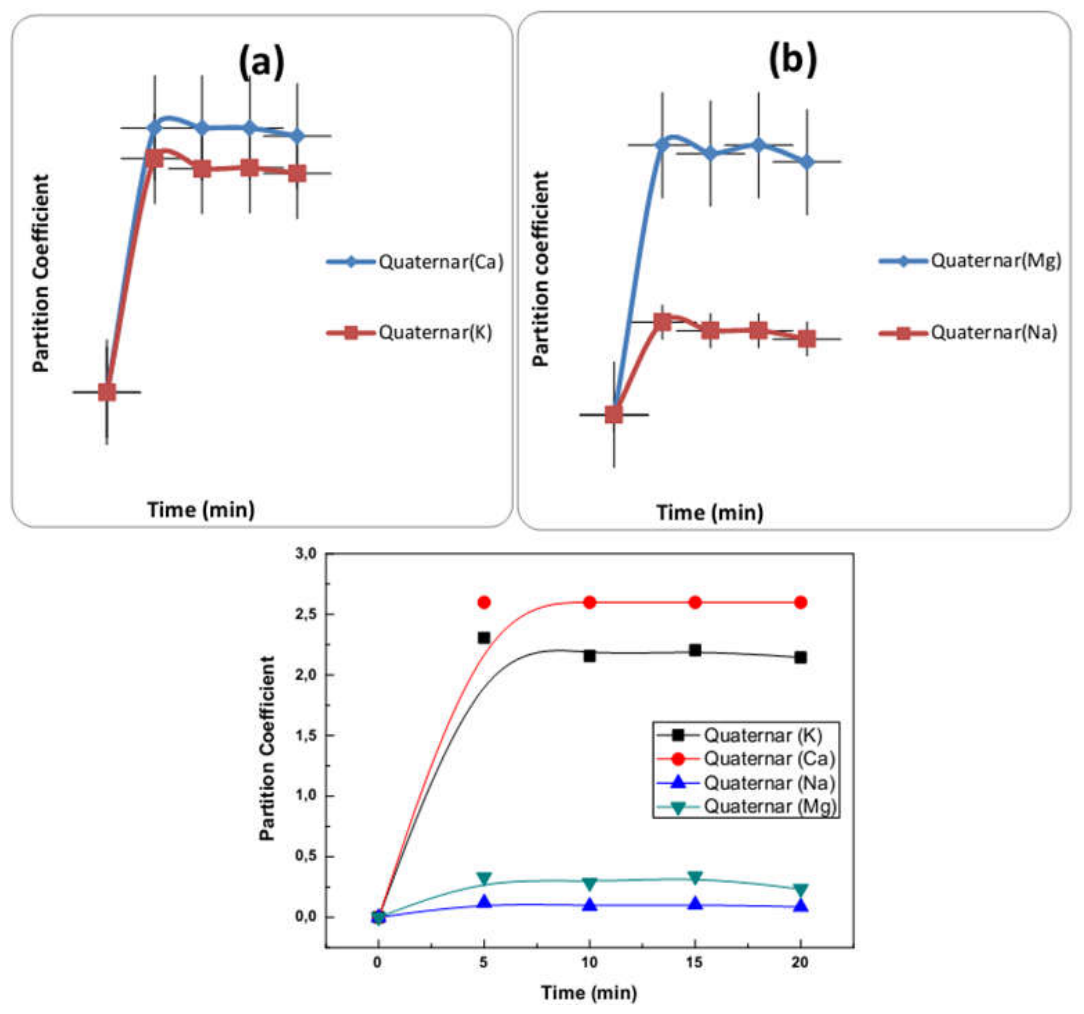

Figure 4. Partition coefficient in the quaternary mixtures.

Exchange cations in the grape juice

Bentonite was placed in contact with a solution containing grape juice freshly squeezed for 20 min with stirring at $40 \mathrm{rpm}$.

Table 2. Concentration of cations present in the grape juice and $\mathrm{pH}$ determined before and after exchange $(\mathrm{n}=4)\left(\mathrm{Ca}^{2+}\right.$ and $\mathrm{Mg}^{2+}$ determined by photometer brand JENWAY PFP7, $\mathrm{K}^{+}$and $\mathrm{Na}^{+}$determined by plasma torch brand VISTA-PORO).

\begin{tabular}{|c|c|c|c|}
\hline Element & $\begin{array}{c}\text { Concentration }(\mathrm{mg} / \mathrm{L}) \\
\text { before exchange }\end{array}$ & $\begin{array}{c}\text { Concentration }(\mathrm{mg} / \mathrm{L}) \\
\text { after exchange }\end{array}$ & Equilibrium constant \\
\hline $\mathrm{Ca}^{2+}$ & 124 & 70.6 & $29.61087 \pm 8.7 \times 10^{-5}$ \\
\hline $\mathrm{Mg}^{2+}$ & 48.4 & 57.2 & $22.9540 \pm 1 \times 10^{-4}$ \\
\hline $\mathrm{K}^{+}$ & 49.6 & 31.6 & $15.1056 \pm 4 \times 10^{-4}$ \\
\hline $\mathrm{Na}^{+}$ & 33 & 35 & $4.96636 \pm 6 \times 10^{-5}$ \\
\hline $\mathrm{pH}$ & $4.6 \pm 0.1$ & $3.6 \pm 0.1$ & - \\
\hline
\end{tabular}

We note from the results that the exchange occurred only for cations $\mathrm{Ca}^{2+}$ and $\mathrm{K}^{+}$, as we have seen in the exchange of a synthetic solution containing the quaternary. This can be explained by the fact that the calcium and potassium ionize more easily based on the values of the atomic volumes. This result conforms to $\mathrm{pH}$ values obtained. Indeed, we observe a decrease in $\mathrm{pH}$ during cation exchange (Table 2).

Bull. Chem. Soc. Ethiop. 2020, 34(1) 


\section{CONCLUSION}

Based to the results obtained in this study, we can conclude that, the use of clarifiers separately gave removal rates than average. Indeed, we have eliminated up to $73.7 \%$ of tannins present in the freshly squeezed juice with gelatin and $83.3 \%$ with bentonite. The combination of gelatine and bentonite increased the percentage of elimination disorder. The best percentage of elimination for freshly squeezed juice has been obtained at the concentration equal to $600 \mu \mathrm{L}$ in gelatin and $950 \mu \mathrm{L}$ in bentonite with a removal rate of $95.7 \%$. After optimization of parameters for clarification, we are also interested in the stability of juice clarification. We can conclude from the accelerated stability test that the treated juice possesses has a good microbiological quality. The filing occurred during storage results from $4.3 \%$ of the trouble that we have not eliminated.

The behavior of Algerian bentonite in contact cations $\mathrm{Ca}^{2+}, \mathrm{Mg}^{2+}, \mathrm{K}^{+}$and $\mathrm{Na}^{+}$were followed. We contacted a synthetic solution containing different cations either alone or in quaternary using batch method. Affinity bentonite with cations was observed separately in the following order: $\mathrm{Ca}^{2+}>\mathrm{Mg}^{2+}>\mathrm{K}^{+}>\mathrm{Na}^{+}$. A time reactivity of 20 min was sufficient to reach equilibrium and the partition coefficients calculated confirm the results obtained. During the clarification, the results show that the cationic exchange between the clay and the various cations present in the juice takes only for ions calcium and potassium.

\section{ACKNOWLEDGEMENTS}

We are grateful to CNRS for providing a financial support to S. Mazrou at "Institut Européen des Membranes (IEM), Unité Mixte de Recherche no. 5635, CNRS", Montpellier Cedex 5, France. All the authors express sincere grateful thanks to William N. Setzer Professor Emeritus Professor of Chemistry, University of Alabama in Huntsville for improving English and F. Bengouia, A. Boukahel, A. Gaiche, H. Lekhal and F. Nait Ali for their keen interesting and their contribution to improve the present manuscript.

\section{REFERENCES}

1. Akretche, D.E.; Kerdjoudj, H.; Gavach, C. Electrodialysis of copper-thiourea solutions. Hydrometallurgy 1993, 34, 231-238.

2. Mazrou, S.; Messaoudi, M.; Begaa, S.; Akretche, D.E. Identification, purification and quantification of toxins "Ochratoxin A" in Algerian grape juice. Algerian J. Eng. Technol. 2019, 1, 2-10.

3. Begaa, S.; Messaoudi, M. Toxicological aspect of some selected medicinal plant samples collected from Djelfa, Algeria Region. Biol. Trace Elem. Res. 2019, 187, 301-306

4. Ramezani, M.; Ferrentino, G.; Morozova, K.; Kamrul, S.M.H.; Scampicchio, M. Clarification of apple juices with vegetable proteins monitored by multiple light scattering. $J$ Food Sci. 2020. DOI: 10.1111/1750-3841.14984.

5. Chatterjee, S.; Chatterjee, S.; Chatterjee, B.P.; Guha, AK. Clarification of fruit juice with chitosan. Process Biochem. 2004, 39, 2229-2232.

6. Lee, W.C.; Yusof, S.; Hamid, N.S.A.; Baharin, B.S. Effects of fining treatment and storage temperature on the quality of clarified banana juice. LWT-Food Sci. Technol. 2007, 40, $1755-1764$.

7. Rungsardthong, V.; Wongvuttanakul, N.; Kongpien, N.; Chotiwaranon, P. Application of fungal chitosan for clarification of apple juice. Process Biochem. 2006, 4, 589-593.

8. Sun, J.; Guo, Y.; Xue, J.; Niu, P. Innovation and practice of separation pre-pressing technology and whole apple utilization. J. Food Process Technol. 2016, 7:8. DOI: 
10.4172/2157-7110.1000614.

9. Ortega, N.; De-Diego, S.; Perez-Mateos, M.; Busto, MD. Kinetic properties and thermal behaviour of polygalacturonase used in fruit juice clarification. Food Chem. 2004, 88, 209 217.

10. Tajchakavit, S.; Boye, J.I.; Bélanger, D.; Couture, R. Kinetics of haze formation and factors influencing the development of haze in clarified apple juice. Food Res. Int. 2001, 34, 43140.

11. Karmakar, S.; De, S. Pectin Removal and Clarification of Juices in Separation of Functional Molecules in Food by Membrane Technology, Elsevier: Amsterdam; 2019; pp. 155-194.

12. Nazir, Z.; Ijaz, S.; Gul, R.; Saleem, M. Purification and characterization of an acidic polygalacturonase from grapes and its potential to improve juice quality. Pak. J. Zool. 2019, $51,1387-1402$.

13. Awe, S. Effect of clarifying agents (gelatin and kaolin) on fruit wine production. Int. J. Agric. Innov. Res. 2018, 6, 130-132.

14. Paraman, I.; Sharif, M.K.; Supriyadi, S.; Rizvi, S.S.H. Agro-food industry byproducts into value-added extruded foods. Food Bioprod Process. 2015,96,78-85.

15. Gulec, H.A.; Bagci, P.O.; Bagci, U. Clarification of apple juice using polymeric ultrafiltration membranes: A comparative evaluation of membrane fouling and juice quality. Food Bioprocess Technol. 2017, 10, 875-885.

16. Klimczak, I.; Małecka, M.; Szlachta, M.; Gliszczyńska-Świgło, A. Effect of storage on the content of polyphenols, vitamin $\mathrm{C}$ and the antioxidant activity of orange juices. J. Food Compos. Anal. 2007, 20, 313-322.

17. Mousavinejad, G.; Emam-Djomeh, Z.; Rezaei, K.; Khodaparast, M.H.H. Identification and quantification of phenolic compounds and their effects on antioxidant activity in pomegranate juices of eight Iranian cultivars. Food Chem. 2009, 115, 1274-1278.

18. Vinson, J.A.; Su, X.; Zubik, L.; Bose, P. Phenol antioxidant quantity and quality in foods: Fruits. J. Agric. Food Chem. 2001, 49, 5315-5321.

19. Yokoi, H.; Obita, T.; Hirose, J.; Hayashi, S.; Takasaki, Y. Flocculation properties of pectin in various suspensions. Bioresour. Technol. 2002, 84, 287-290.

20. Boukerroui, A.; Ouali, M.S. Activation d'une bentonite par un sel d'ammonium: Évolution de la capacité d'échange et de la surface spécifique in Annales de Chimie Science des Matériaux, Elsevier: Amsterdam; 2000; pp. 583-590.

21. Erdogăn, B.; Demirci, Ş.; Akay, Y. Treatment of sugar beet juice with bentonite, sepiolite, diatomite and quartamin to remove color and turbidity. Appl. Clay Sci. 1996, 11, 55-67.

22. Vladisavljević, G.T.; Vukosavljević, P.; Veljović, M.S. Clarification of red raspberry juice using microfiltration with gas backwashing: A viable strategy to maximize permeate flux and minimize a loss of anthocyanins. Food Bioprod. Process. 2013, 91, 473-480.

23. Igual, M.; García-Martínez, E.; Camacho, M.M.; Martínez-Navarrete, N. Effect of thermal treatment and storage on the stability of organic acids and the functional value of grapefruit juice. Food Chem. 2010, 118, 291-299.

24. Carlberg, C. Statistical Analysis, Microsoft Excel 2013, Que Publishing: USA; 2014. 